This is a self-archived - parallel published version of this article in the publication archive of the University of Vaasa. It might differ from the original.

\title{
Combining value and momentum: evidence from the Nordic equity market
}

Author(s): Grobys, Klaus; Huhta-Halkola, Topi

Title: Combining value and momentum: evidence from the Nordic equity market

Year: $\quad 2019$

Version: Accepted manuscript

Copyright (C) 2019 Informa UK Limited, trading as Taylor \& Francis Group. This is an Accepted Manuscript of an article published by Taylor \& Francis in Applied economics on 22 February 2019, available online:

http://www.tandfonline.com/10.108o/ooo36846.2018.1558364

Please cite the original version:

Grobys, K., \& Huhta-Halkola, T., (2019). Combining value and momentum: evidence from the Nordic equity market. Applied economics 51(26), 2872-2884. https://doi.org/10.1080/ooo36846.2018.1558364 


\title{
COMBINING VALUE AND MOMENTUM: EVIDENCE FROM THE NORDIC EQUITY MARKET
}

Klaus Grobys ${ }^{1 \mathrm{a}}$

Topi Huhta-Halkola ${ }^{1 b}$

\begin{abstract}
This is the first paper that explores Fisher, Shah and Titman's (2016) average ranking approach for the value and momentum strategy in the Nordic equity market offering an exceptional experimental environment. Our results indicate that in the Nordic stock markets, the value anomaly offered excess returns in the 1993 to 2017 sample period only when small stocks were a part of the portfolio, whereas the momentum effect is strong and significant, irrespective of size. Interestingly, our findings also indicate that the negative correlation between value and momentum (Asness, Moskowitz and Pedersen, 2013) seems to be driven by growth stocks: Winner stocks that are value stocks generated $1.66 \%$ per month on average, whereas winner stocks that are growth stocks exhibit virtually the same average payoff. On the other hand, the spread between value and growth stocks that are loser stocks is on average $0.97 \%$ per month.
\end{abstract}

Keywords: Nordic stock markets, value, momentum, average ranking method, negative correlation

JEL classification: G12, G14

${ }^{1}$ We are grateful to an anonymous reviewer to having received valuable comments.

${ }^{a}$ K. Grobys

Department of Accounting and Finance, University of Vaasa, Wolffintie 34, 65200 Vaasa, Finland

e-mail: klaus.grobys@uwasa.fi; grobys.finance@gmail.com

b T. Huhta-Halkola

Department of Accounting and Finance, University of Vaasa, Wolffintie 34, 65200 Vaasa, Finland e-mail: topi.huhta-halkola@elisa.fi 


\section{INTRODUCTION}

In the 21 st century, value investing has become increasingly popular. The finance industry offers mutual funds, ETFs and hedge funds that fixate merely on value investing. The principle behind this fixation is the value premium. Many financial institutions have also funds exploiting the momentum effect. There are even funds that combine both strategies into one product, such as AQR's International multi style fund. ${ }^{1}$ The reason for why such funds have gained huge popularity among investors is the empirical evidence that value stocks have outperformed growth stocks in the past while at the same time winner stocks have beaten loser stocks.

Earlier studies have suggested that value and momentum strategies earn abnormal riskadjusted returns (Stattman 1980, Jegadeesh and Titman 1993). Most of the prior studies have concentrated on showing the existence of value and momentum anomalies separately. On the other hand, in an early paper Asness (1997) discovered a negative correlation between value and momentum. Value was strongest among loser stocks, whereas momentum was strongest in growth stocks. Similar findings were documented in Daniel and Titman (1999). A negative correlation among two high-yielding anomalies possibly offers an opportunity to earn high returns at a relatively low portfolio risk. Asness, Moskowitz and Pedersen (2013) studied the correlation and performance of value and momentum anomalies as well as the performance of combo strategies across eight asset classes and markets. They found significant negative correlations between value and momentum strategies; value and momentum earning excess returns in all investigated markets and asset classes except for Japan where momentum does not yield any significant payoffs. Especially a portfolio that combined both strategies improved the overall performance in terms of Sharpe ratio and performed remarkably well. They argue that the negative performance of the momentum strategy in Japan should not be viewed in solitude but in the context of value and momentum combination: In the selected time period, value performed exceptionally well in Japan. The study used extensive time series from 70 s to the 2010 s. $^{2}$

Furthermore, Fisher, Shah and Titman (2016) studied the portfolio implementation of momentum and value anomalies. Unlike Asness et al. (2013) they studied long-only portfolios in

\footnotetext{
${ }^{1}$ See https://funds.aqr.com.

2 Another paper that documents negative correlation between value and momentum is Cakici, Fabozzi and Tan (2013) who studied the size, value and momentum in 18 emerging markets and found strong evidence for value in all the markets and for momentum in all investigated markets excluding Eastern Europe. They also found that value and momentum are negatively correlated which is in line with previous studies. Their time period started from January 1990 and ended in December 2011 covering regions from Asia, Latin America and Eastern Europe.
} 
U.S. stock market covering a sample from 1975 to 2013 and used several approaches to combine the anomalies into long-only portfolios. All of the approaches increased Sharpe ratios in comparison to the market in both small and large stocks. Their study shows that more sophisticated combination portfolios outperformed the simple 50/50 combination proposed in Asness et al. (2013). While there is a wide strand of finance literature that explores emerging markets, there are surprisingly few studies available focusing on the Nordic stock markets. One paper that is relevant to our study is that of Leivo (2012), who explored the Finnish stock market data, covering the period 1993 to 2009 and found that enhancing value by incorporating momentum improves most of the traditional value-only portfolios. However, he found that including momentum metrics into the portfolios increases the asymmetry of return distribution in an undesirable manner for investors. ${ }^{3}$

The purpose of this paper is to investigate the profitability of combined value and momentum strategies using mainly blue chips in the Nordic countries. Using a long sample period of 25 years, covering data from 1993 to 2017, the current research attempts to uncover ideal portfolio implementation techniques that will potentially improve the risk-return profiles of simple pure-play value or momentum strategies. Thereby, it is also investigated which strategies generate the highest raw returns and risk-adjusted returns. Since stocks in the Nordic equity markets are not only euro but also in Swedish crones, Norwegian crones and Danish crones, all stocks are adjusted for the corresponding exchange rates and converted into euro. Finally, this study explores also what may be the underlying driver of the correlation structure between value and momentum by making use of double-sorted portfolios.

The current research contributes to the literature by focusing exclusively on the Nordic stock markets that involve very different features compared to the U.S. equity market. Fama and French (2008) underline the importance of examining whether anomalies are pervasive across size groups, for instance. Such statements make it surprising that no study has yet been

\footnotetext{
${ }^{3}$ Other relevant papers that investigate the profitability of strategies combining value and momentum are Bird and Whitaker (2004) and Bird and Casavecchia (2007). Bird and Whitaker (2004) discovered that the value anomaly can be significantly improved with a combination of momentum while adding dispersion to the strategy improves the pay offs even more. They argue that their findings affirm that many stocks go through a cycle similarly as Lee and Swaminathan (2000) suggest. The time period that they considered covered a sample from 1990 to 2002 and accounting for German, French, Italian, Dutch, Spanish, Swiss and British stock markets. On the other hand, Bird and Casavecchia (2007) studied whether value strategies could be enhanced using momentum indicators to time stock purchases. The study employed a sample running from 1989 to 2004 and European data. Confirming earlier studies, they found that that value strategies could be considerably enhanced.
} 
undertaken to investigate the payoffs of combined value and momentum strategies in periphery markets involving highly developed economies such as the Nordic equity markets. The same argument as raised in Grobys (2016, p.3) is also valid in the context of our study: we view the Nordic equity market setting as an exceptional experimental environment controlled ex ante for industrialization and liquidity. In doing so, we extend Leivo's (2012) study as we also account for the Swedish, Norwegian and Danish stock markets, and we expand the data series incorporating eight years of more data. Furthermore, our study also complements Fisher et al. (2016) and by investigating not only long-only strategies but also zero-cost portfolios incorporating short legs while it also extends Asness et al. (2013) by employing double-sorted portfolios to reveal what may be the underlying driver of the negative correlation between value and momentum. While long-only strategies are perhaps more relevant for the mutual funds industry and retail investors, zero-cost strategies are typically employed in the hedge-funds industry. Finally, our paper adds to the wide strand of literature investigating the profitability of strategies combining value and momentum (Bird and Whitaker, 2004; Bird and Casavecchia, 2007; Leivo, 2012; Asness et al., 2013).

Our results indicate that in the Nordic stock markets, the value anomaly offered excess returns in the 1993 to 2017 sample period only when small stocks were a part of the portfolio. When implemented among the largest companies, the average payoff of the zero-cost strategy drops from $1.25 \%$ per month to $0.44 \%$ per month and does not reach statistical significance on a common 5\% level. Confirming earlier studies, the momentum anomaly generates raw excess returns corresponding to $1.72 \%$ per month when all stocks are included and $0.86 \%$ per month when implementing this strategy among large stocks only. Both average payoffs are statistically significant even on a $1 \%$ significance level. Confirming Asness at al. (2013), using a simple 50/50 allocation strategy between value and momentum increases Sharpe ratios significantly. Interestingly, our double-sorting approach indicates that the negative correlation seems to be driven by growth stocks: Winner stocks that are value stocks generate $1.66 \%$ per month on average, whereas winner stocks that are growth stocks exhibit virtually the same average payoff. However, the spread between value and growth stocks in the loser group is on average $0.97 \%$ per month. Finally, we find that Fisher et al.'s (2016) recently proposed average ranking method implemented among large stocks generates excess returns corresponding to $1.60 \%$ per month with a Newey-West (1987) $t$-statistic of 7.01 indicating statistical significance on any level. We 
find that, in terms of Sharpe ratio and Sortino ratio, this strategy can be considered superior. Since we investigate mainly large stocks and, by this, implicitly control for liquidity, our results may be also of interest for practitioners in the finance industry.

Our paper is organized as follows. The next section summarizes the features of the Nordic equity markets. The third section describes the empirical setting. The fourth section presents the results and the last section provides concluding remarks.

\section{NORDIC STOCK MARKETS}

Compared to the U.S. equity market, the Nordic stock market is relatively new; yet developed equity market. The market consists of five countries: Denmark, Finland, Iceland, Norway and Sweden. Following earlier studies, we do not account for Icelandic stocks as Iceland is the smallest equity market in terms of market capitalization and therefore often excluded in empirical studies. Foreign ownership of the Nordic stock markets has risen significantly from the early 90ties as the economies have developed and stock markets have become more active in both pure number of stocks and trading volume. These markets are sometimes even referred to as periphery markets which refer to stock markets that are on the outskirt of the investment horizon. A feature of periphery markets is that at times they are highly volatile as in times of distress investors pull their money away from these markets first; which is a side effect of the flight to safety. Nowadays, Nordic countries are often considered part of the European core, although the shift in foreign ownership during crises implies that they still experience some peripheral qualities.

Nordic stock markets started to develop rapidly in the 90ties when the economies started growing at a faster pace. As young but liquid stock markets and exhibiting a low risk environment, the Nordic stock markets offer an interesting opportunity to broaden equity market studies outside of the traditional U.S. scope. Furthermore, compared to emerging market economies, for instance, the Nordic countries have been offering stable political environments with low risk profiles. Moreover, the bond yields of Nordic countries have been very close to U.S. bond yields which is not the case with many other periphery or developing markets: Nordic countries have held constantly a triple-A credit rating with the exception of Finland which is currently rated at the same level as the U.S. Some might even argue that the Nordic stock 
markets are less risky from this standpoint than the U.S.. While the U.S. has been downgraded to the double-A, Denmark, Norway and Sweden still hold triple-A rating. Finally, the Nordic countries are also low in corruption and the stock markets have a relatively high level of liquidity. ${ }^{4}$

While there is a wide strand of research in emerging market economies, surprisingly little attention has been paid to investigating the Nordic stock markets. As pointed in Fama and French (2008), equity market phenomena can be sample-specific and therefore it is important to explore those phenomena in other markets than the U.S. Nordic stock markets offer an excellent opportunity as they are rapidly growing equity markets with increasing liquidity, high level of globalization involving a flourishing export industry, but at the same time they offer lower levels of risk compared to emerging markets.

\section{EMPIRICAL FRAMEWORK}

The data is compiled with OMXH, OMXSPI, OSEBX and OMXC main listed companies' historical returns and financials from January 1991 to December 2017. All stocks that are traded in First North or in other non-main list market places are excluded from the sample. Stocks listed at the Icelandic stock exchange are excluded due to the low amount of traded stocks, trading volume and especially the market capitalizations of those companies. The period that portfolios are held starts from January 1993 and ends at December 2017. From a practical investment perspective, this 25-year period presents the vast majority of the time horizon when Nordic stock markets have been large and active enough for large overseas investors (Leivo, 2012).

If a stock is delisted it will be sold at the closing price of its last trading day. If a stock has gone bankrupt the return on it will be minus 100 percent. The dividends are reinvested to the same stock, eliminating biases arriving from different dividend yields between stocks. The total number of stocks in the sample is high, over 2000 (see Table A.1 in the appendix), due to the fact that all of the stocks that have been traded in the period are included in the sample to provide the best possible real-life investment scenario. This procedure eliminates the survivor bias which would tilt the results to be perhaps more favorable, especially, in a smaller market setting. The large variance in the number of companies, as shown in Table A.1, is explained by the low

\footnotetext{
${ }^{4}$ See https://www.transparency.org/research/cpi/overview.
} 
number of stocks in the early 90ties and the rapid development of Nordic stock markets. Sweden is the largest market as it accounts for almost half of the average number of companies as well as the total market values. Unlike Leivo's (2012) study, Swedish stocks may be the core driver of our results.

This unique set of stocks from several countries collected into one basket offers a liquid set of securities that can actually be traded. Stock returns and market caps from Swedish, Danish and Norwegian companies are converted to euros using month-end exchange rates that are derived from Bloomberg. This approach gives actual returns that investor would have been able to generate. The developments of the corresponding exchange rates are provided in Figure A.1 in the appendix. As it is common practice, financial companies and stocks that are not primary listed in the Nordic exchanges are excluded from the sample; for example if they have primary listing in London but have dual listing in Oslo.

While value portfolios are based on their $\mathrm{P} / \mathrm{B}$ ratios, momentum portfolios are based on their past 12-months total shareholder return excluding the last month (see Asness et al., 2013). ${ }^{5}$ Furthermore, as a risk-free rate 6-month interbank offered rate is used. Specifically, this study employs an average of 6-month Euribor, Stibor, Nibor and Cibor. For the periods prior Euribor, 6-month Helibor is used as a risk-free rate for the Finnish equity market. This method gives the best proxy for a risk-free rate to an investor who invests in the Nordic stock market. ${ }^{6}$ Additionally, a 6-month rate is used instead of a 3-month rate in order to avoid months with negative risk-free rates. Using the 6-month rate gives also a slightly higher average risk-free rate than using the 3-month rate which means that our results are somewhat more conservative. Figure A. 2 in the appendix reveals that the Nordic IBOR-rates have been higher compared to the U.S. T-Bills, with the exception of the most recent years and the years prior to the financial crisis. It is also noteworthy that the Nordic rates are highly positively correlated with the exception of Norway which has its own special circumstances due to the impact of oil price, although it does not differ dramatically from the other rates. Finally, from these IBOR-rates, an average is formed which is used as a risk-free rate in this study.

\footnotetext{
${ }^{5}$ Using total shareholder return instead of simple share price performance avoids unnecessary trading created from large dividend payments creating false signals as share price should drop the amount of dividend paid. This should not have a major impact on the momentum signals but it will avoid repelling stocks with high dividend yields.

${ }^{6}$ Especially in the early 90s, the markets had higher interest rates and therefore higher risk profiles than e.g. U.S. market. Due to this, the country average of 6-month interbank offered rate is preferred to U.S. T-Bill that has been used in some country basket studies in previous academic research.
} 
Further, price-to-book ratios are calculated as the latest share price divided by the last year's actual reported book value per share. The book values are considered to be from last year on the first of July in order to avoid any ahead look biases. Share price data, risk-free rates, stock index returns, foreign exchange rates, market caps and price-to-book ratios are derived from Bloomberg's database. The investment horizon is from 1993 to 2017 corresponding to 25 years of monthly data. This time period includes several market cycles and sentiments offering a comprehensive dataset for research. During the period, the Nordic stock markets have evolved and grown in size as well as experienced turmoil from the tech bubble in the turn of the century to the financial crisis in the later sample. In the final data sample from which the combination portfolios are created the portfolios hold only the top third of the largest stocks based on the market capitalization. This leads to a dataset where the smallest stock in the sample is $65 \mathrm{M} €$ in market capitalization and, on average, all companies are above $175 \mathrm{M} €$ in market capitalization. This leads to a liquid set of securities, although there may be some short sales constraints in medium-sized stocks. This matter is discussed in following chapters.

When constructing portfolios, the aforementioned parameters are used, that is, top and bottom thirds are used as limits for value and growth as well as winners and losers stocks. The portfolios are then rebalanced at the beginning of each month. In a similar manner to risk-free rates, a combined market index is created using all-share indexes from OMX Helsinki, Stockholm, Oslo, and Copenhagen. The returns are total shareholder returns where dividends have been reinvested in a similar manner as in portfolios created in this study. The returns of individual country indexes are additionally value-weighted to avoid bias from having a too high portion of the returns from smaller countries. It is important to note that the indices will have returns also from the smaller stocks, hence creating larger returns compared to an index compiled from only the largest stocks in the market. Again, our conservative approach creates a larger hurdle to surpass for the (combined) portfolios investigated in this study.

In line with the earlier literature, portfolio performance is measured by Sharpe ratio and Sortino ratio. Also, absolute returns are presented and compared as well as risk-adjusted returns measured by the Capital Asset Pricing Model. The performance of the formed value and momentum combination portfolios are compared to the combined index as well as simple separate value and momentum portfolios. 
In addition to pure play value and momentum portfolios, several types of value and momentum combination portfolios are created:

50/50: half of the portfolio invested in momentum and the other half in value.

(2) Double screening: stocks that indicate both value and momentum signals (in the top 50\% for both strategies for the long leg, and in the bottom 50\% for both strategies for short leg).

(3) Ranking scheme: ranking stocks based on value and momentum and taking the average of the scores (long for top third and short for lowest third)

Every portfolio will be constructed as long-only and long-short portfolio; hence the number of portfolios will be treble to the strategies presented above plus the pure-play value and momentum portfolios. Long-only is studied conservatively due to the fact that only large stocks are included in the sample. The large cap tiers are adjusted monthly so if a stock has been in the portfolio but the share price declines, it may be sold if the drop-in share price causes the stock to fall below the top $50 \%$ in market capitalization. This procedure offers an even more liquid set of securities reducing short-sales constraints and transaction costs compared to small cap stocks. Additionally, returns are then equal-weighted creating a liquid set of returns and leaving very little room for short sales constraints, high trading costs or non-viable trades. Later on we will see that equal-weighting additionally supports momentum while diminishing value payoffs. Value-weighted returns are not investigated due to very large stocks causing massive bias.

Instead of using value-weighted returns, equal-weighted returns are employed due to the fact that in the Nordic stock markets there are not that many very large companies and their returns would dominate when making use of value weighted returns. For example, in the early 2000 s, Nokia's market cap was more than $25 \%$ of the total market value of all stocks in the Nordic stock market. This creates situations where one stock's weight is more than half of the long or short leg portfolio, implying that the portfolio's performance would be almost solely driven by one stock. Hence, the current research focuses on equal-weighted returns because it provides the best representation of the returns that could actually have been achieved. Similarly, equal-weighted returns have been used in other Nordic stock market studies (Davydov, Tikkanen and Äijö, 2016, Leivo and Pätäri, 2009; Leivo, 2012). However, our study accounts for the size effect by conditioning sorts on stocks that either are in the top third or in top $50 \%$ in terms of market capitalization. 
To avoid a small-firm bias, only larger stocks are included in the sample when comparing the best combination strategies. However, in pure-play value and momentum portfolios also smaller stocks are included to show the effect that size has to value and momentum strategies. The conservative approach of using only the large stock is then applied when studying the bestin-class value and momentum combinations. To adjust for possible autocorrelation and heteroscedasticity, Newey-west covariance estimator is used.

\section{RESULTS}

Firstly, we expect that we are able to confirm earlier studies by revealing the existence of a value and momentum premium in our Nordic market setting. Secondly, we expect that a 50/50 combination of the two strategies (Asness et al., 2013) and an average ranking method (Fisher et al., 2016) will outperform value-only and momentum-only strategies. However, it is unclear which one of those combination strategies will produce the highest risk-adjusted returns. Further, all combination portfolios are also expected to outperform the market measured by our combined country index.

\subsection{Pure-play momentum and value strategies}

The momentum strategy offered significant excess returns in the Nordic stock market during the period. Although momentum performed well, Figure 1 shows that the strategy suffered some severe crashes during the period, as it has been identified by earlier research (Barroso and SantaClara, 2015; Daniel and Moskowitz, 2016; Grobys, 2016).

The results reported in Panel A and B of Table 1 show that the winner-minus-loser portfolios offer highly significant average payoffs for both samples all-stocks and large stocks. The results are significant on at least 5\% level. Moreover, comparing Panel B with Panel A of Table 1 shows that the Sharpe ratio even increases in large-stock portfolios compared to allstocks, although it delivers lower alpha and Sortino ratio. This is due to the relatively higher volatility of the all-stocks momentum portfolio. As the Sortino ratio does not account for the upside risk, it does not increase when we move to the large-stocks only portfolio. The momentum strategy is tilted towards growth as the $\mathrm{P} / \mathrm{B}$ ratio of the winner-portfolio is 7.2 , on average, whereas the corresponding figure for the loser-portfolio is estimated at only 3.7 in the 
top third portfolio. In the all-stocks portfolio the difference is even larger as the winner-portfolio has over triple the $\mathrm{P} / \mathrm{B}$ ratios of the loser-portfolio, although now the ratios are a lot lower, winners having 2.1 and losers having 0.7 , on average.

Furthermore, the results reported in Panel A of table 2 indicate that the value anomaly offered excess returns in the Nordic stock market over our 25 years sample period when small stocks were a part of the portfolio. On the other hand, the results reported in Panel B of table 2 provide evidence that after accounting for size, the returns were significantly lower: Even though the value anomaly yielded impressive returns corresponding to $1.25 \%$ per month in the whole sample period, Figure 1 also shows that it suffered long periods of low returns which can be one of the reasons why investors avoid value strategies (Lakonishok, Shleifer and Vishny, 1994). Our results imply that the value anomaly seems to be partially driven by small stocks as equally weighted returns of the whole sample offer significantly higher returns compared to the universe of stocks that are in the top third by market capitalization. The zero-cost value minus growth portfolios generated high Sharpe ratios corresponding to 1.11 and 0.44 , respectively.

\subsection{0/50 combination portfolio}

The correlation matrix between momentum and value strategies for the top third largest companies is reported in Table A.2. in the appendix. Confirming earlier studies, the correlation between the zero-cost value and momentum portfolios over the sample period is negative with a point estimate of -0.43 which is close to the corresponding point estimate of -0.53 reported in Table 2 in Asness et al. (2013) for the U.S.. Furthermore, using a very simple 50/50 allocation between the aforementioned value and momentum portfolios increases Sharpe ratios significantly as the negative correlation between the strategies reduces the standard deviation of the combined portfolio. The results are reported in Table 3 and Figure 1. The 50/50 combination clearly adds value as Sharpe and Sortino ratios improve considerably compared to pure-play strategies. The improvement of Sharpe ratios gives strong evidence that the combination of value and momentum indeed reduces the overall portfolio risk compared to individual value or momentum strategies, whereas the weak returns of the value strategy are compensated with high momentum returns. Interestingly, the results are similar to the corresponding results documented in Assnes et al. (2013) with respect to the Japanese stock market, though the roles between the hero and zero are reversed. The spread of the $50 / 50$ portfolios are statistically significant at a $1 \%$ 
level. Due to a lowered portfolio standard deviation, the robust $t$-statistics are higher than in either of the portfolios corresponding to the pure-play strategies.

\subsection{Double screening for value and momentum}

Asness at al. (2013) do not employ double sorts to investigate what is the underlying driver of the strategies' negative correlation. Therefore, we explore this issue in detail. In doing so, we only employ the stocks in the top third of the market capitalization in order to exclude small stocks that do not exhibit reasonable levels of liquidity or might be subject to short sales constraints. While the previous analysis employed tercile sorts for setting the limits, in the following analysis the value and momentum limits are set to $50 \%$ in order to have enough stocks in the portfolios at all times because stocks must have both value and momentum signals to be included in the portfolio. That means, stocks are sorted based on momentum and value independently, that is, they are not firstly sorted based on value and then on momentum within the value stocks which would correspond to a dependent sorting approach. ${ }^{7}$ The results of the $50 \%$-limits portfolios are presented in Table 4. Combining value and momentum metrics into one portfolio increases returns significantly. We observe that the value and winner portfolio creates high average returns corresponding to $1.66 \%$ per month. Surprisingly, the growth and winner portfolio creates even slightly higher returns, corresponding to $1.68 \%$ per month, implying that momentum is the driver of the high average payoffs. It may be interesting to note that the returns of the two aforementioned portfolios are highly correlated throughout the sample period which is also noticeable by visual inspection of Figure 2 where the payoff evolutions of the portfolios reported in Table 4 are plotted against time. It is also worth noting that even the value and loser portfolio creates excess returns corresponding to $1.22 \%$ per month which is statistically significant on a $1 \%$ level.

The worst performing portfolio is the growth and loser portfolio which yields even lower returns than the risk-free rate in our sample period offering interesting short sales opportunities. As we only account for large stocks exhibiting high levels of liquidity, this strategy would be implementable in real life also. Our findings may be consistent with Lee and Swaminathan (2000) who suggest that momentum experiences different cycles. Similar results were also found

\footnotetext{
${ }^{7}$ The average number of included stocks in the portfolios is reported in table A.3. in the appendix. Table A.3. shows that this approach yields well diversified portfolios.
} 
by Bird and Whitaker (2004) in major European stock markets accounting for a sample period from 1990 to 2002. Contrary to this study, they found that the most prolific long play would have been value and losers rather than value and winners.

After controlling for the correlation with the market, the value and winner portfolio offers the highest average payoff corresponding to $0.72 \%$ per month which is statistically significant at a $1 \%$ significance level. Due to the correlation between value and loser stocks, the alpha is estimated at $0.18 \%$ per month and statistically not different from zero. The growth and winner portfolio delivers significant alpha and raw returns also. The economic magnitudes of the Sharpe and Sortino ratios are close to figures for the value and winner portfolio. Strikingly, the growth and loser portfolio creates statistically highly significant negative alpha corresponding to $-0.88 \%$ per month.

\subsection{Average ranking method}

The average ranking method ranks stocks from 1 to 0 based on their ranking in price to book and cumulative past performance compared to the other stocks. Lowest price to book ratio (highest value) gets 1 and highest (lowest value) gets 0 and the stock that is in the median position in the sorted stocks sample gets 0.5 as ranking score. Similarly, highest cumulative past return gets the score of 1 and lowest gets 0 . Then these ranks are added together and based on that score the top third of the companies creates a long portfolio (high rank) and lowest third creates a short portfolio (low rank).

This procedure allows stocks to be part of the portfolio even if they do not have both signals but are high in another. It may also include stocks that are neither value nor momentum but score relatively high on both measures. In doing so, we extend the average ranking method proposed in Fisher et al. (2016) by constructing a short portfolio also. The advantage of this approach compared to double screening is that it lowers the portfolio turnover; hence it is not solely driven by momentum. Table 5 shows that implementing strategies based on average ranking value and momentum signals indeed yields significant excess returns. Again, we account for size by using only the top third of the largest stocks in our sample.

From Table 5 we observe that the high minus low strategy generates average excess returns of $1.60 \%$ per month during the sample period with Sharpe and Sortino ratios corresponding to 1.81 and 16.44 , respectively. Both measures are considerably higher than those 
for the 50/50 portfolio reported in Panel B of Table 3. We find that the high-rank portfolio generates both high average raw payoff and alpha, corresponding to $1.85 \%$ per month and $0.90 \%$ per month, respectively, which are statistically significant at a $1 \%$ level. ${ }^{8}$ The time series evolutions of the portfolios reported in Table 5 are plotted in Figure A.3 in the appendix. ${ }^{9}$ Moreover, the correlation matrix reported in Table A.3. in the appendix shows that all investment vehicles are negatively correlated with the index but are highly positively correlated with each other.

In the presence of short sales constraints, the returns from combination portfolios might be substantially reduced. Comparing the long-only portfolios, we find that the high rank portfolio exhibits a Sharpe ratio (e.g., 1.18) that is virtually the same as the one of the winner portfolio (e.g., 1.16), although it is worth noting that accounting for transaction costs would lower the winners portfolios' returns. As a consequence, the ranking scheme portfolio appears to be superior. The average turnovers of different value and momentum portfolios documented in Fisher et al. (2016) indicate that momentum clearly has the highest turnover with both buy and sell thresholds with figures ranging between $104 \%$ to $157 \%$, whereas value involves the lowest turnover with corresponding figures ranging between $20 \%$ and $31 \%$ which is in line with the common belief that value is a fast-moving signal and momentum a slow-moving one. Naturally, the 50/50 combo portfolio exhibits lower turnover than momentum and average ranking scheme accounting for turnovers ranging between $62 \%$ and $103 \%$, whereas the average ranking scheme generates turnovers between $62 \%$ and $103 \%$.

\footnotetext{
${ }^{8}$ Note that growth stocks are, on average, larger in size than value stocks, and including only the largest third of the stocks in the portfolio decreases the probability of any short-sale constraints considerably.

${ }^{9}$ Fisher et al. (2016) documented that the average ranking method decreases portfolio turnover compared to momentum portfolio and therefore trading costs significantly, although it has a higher turnover compared to the $50 / 50$ portfolio that benefits from the low turnover of the value portfolio. Using thresholds in trading as in Fisher et al. (2016) would decrease the portfolio turnover even more.
} 


\subsection{Performance during the Global financial crisis}

Another interesting issue is to explore the performance of our proposed strategies during the financial crisis and the European debt crisis, respectively. ${ }^{10}$ Larry Elliott argues in his commentary Global financial crisis: five key stages 2007-2011 that the first phase of the global financial crisis began on 9 August 2007 with the seizure in the banking system precipitated by BNP Paribas announcing that it was ceasing activity in three hedge funds that specialised in US mortgage debt, whereas 9 May 2010 marked the point at which the focus of concern switched from the private sector to the public sector due to the severe problems in Greece. ${ }^{11}$ Since the financial crisis flowed into the European debt crisis, we consider the performance of our zerocost strategies during the sample period January 2008-December 2010. ${ }^{12}$ Since practitioners maybe mostly interested in large stocks, we focus in our analysis exclusively on stocks that are in the top-third in terms of market capitalization. In Table 6 we report the average payoffs of the 50/50 combination portfolio, high rank-low rank zero-cost portfolio, and the value and winnersgrowth and losers zero-cost portfolio using large stocks only. As it is from a practitioner's point of view interesting to see how our proposed strategies performed relative to the 50/50 combination benchmark portfolio, we also report the difference between those average payoffs and the 50/50 combination portfolio, which serves here as the benchmark strategy. From Table 6 we observe that both the 50/50 combination portfolio and the high rank-low rank zero-cost portfolio generate statistically significant payoffs, whereas the value and winners-growth and losers zero-cost portfolio does not. Strikingly, the payoff differential between the high rank-low rank and $50 / 50$ combination portfolio is $0.71 \%$ per month and statistically significant on a $5 \%$ level. As a result, this additional robustness check supports our earlier findings even for the challenging period of the Global financial crisis, that is, the ranking scheme-based portfolio is superior in terms of its performance relative to the other strategies.

\footnotetext{
${ }^{10}$ We are grateful for an anonymous reviewer to highlighting this issue.

${ }^{11}$ Larry Elliott is Economics editor of The Guardian and his article Global financial crisis: five key stages $2007-$ 2011 was published online on Sunday 7 August 2011 16.49 BST.

12 This sample period is in essence also covered in Grobys' (2015) paper exploring the performance of different momentum strategies in the European Monetary Union during the financial crisis and European debt crisis. In his paper, however, he employs three different dummy variable models that have a crisis dummy having a value of zero either before the pre-January 2008 period or before the pre-January 2007 period or before the pre-January 2009 period and a value of zero otherwise. However, his approach does not define the end of the crisis period and neither does it account for the issue that the financial crisis flowed into the European debt crisis. Our approach accounts for both of these issues.
} 


\section{CONCLUSION}

The popular momentum strategy yields significant excess returns in the Nordic stock market that are unrelated to size. The value strategy offers significant average payoffs but after accounting for size those returns decrease, implying that value premium is partly but not fully driven by a size effect in the Nordic stock market. Combining value and momentum increases Sharpe ratios and offers investors significant diversification benefits in the Nordic stock markets which is in line with previous studies (Asness et al., 2013; Fisher et al., 2016). All of the investigated combination portfolios improved the Sharpe ratios of pure-play strategies. Specifically, we found that the ranking scheme-based portfolio offered the best performance. All of the explored combination portfolios also exhibited higher raw returns than pure-play strategies except for the $50 / 50$ portfolio; though it had a higher Sharpe ratio than pure-play strategies due to reduced portfolio volatility.

Further research could be done with additional momentum metrics, such as employing three-month or one-month past performance measures, additional value metrics, such as PE or EV/EBIT ratios, or even more exotic ways to combine the metrics. Additionally, analyst forecasts, profitability or asset growth could be analyzed to better understand the anomalies. This paper does not explicitly take into account trading costs but rather focuses on the highest gross returns within a liquid set of securities, although it is noted that, based on previous research, momentum experiences higher transaction costs than value. Future research could account for trading costs for the portfolios, e.g. based on the actual spreads for each specific stock at the date the trade is executed. Also, the scope of the research could be broadened to other markets and time periods. Neither does this paper account for the fact that some sophisticated momentum strategies, such as risk-managed momentum strategies (Barroso and Santa-Clara, 2015; Moreira and Muir, 2017; Grobys, 2018), could increase Sharpe ratios of the underlying simple strategy by avoiding momentum crashes. Future research is encouraged to combine these streams of research. 


\section{References}

Asness, C.S. (1997). The Interaction of Value and Momentum Strategies. Financial Analysts Journal 29-36.

Asness, C., Moskowitz, T. \& L. Pedersen (2013) Value and Momentum Everywhere. Journal of Finance 68, 929-985

Barroso, P. \& P. Santa-Clara (2015). Momentum has its moments. Journal of Financial Economics 116, 111-120.

Bird, R. \& J. Whitaker (2004). The performance of value and momentum investment portfolios: Recent experience in the major European markets Part 2. Journal of Asset Management 5, 157175

Bird, R. \& L. Casavecchia (2007). Value enhancement using momentum indicators: the European experience. International Journal of Managerial Finance 3, 229-262

Daniel, K. \& S. Titman (1999). Market Efficiency in an Irrational World, Financial Analysts Journal 55, 28-40.

Daniel, K. \& T. Moskowitz (2016). Momentum crashes, Journal of Financial Economics 122, $221-247$

Davydov, D., Tikkanen, J. \& J. Äijö (2016). Magic Formula vs. Traditional Value Investment Strategies in the Finnish Stock Market. Nordic Journal of Business 65, 38-54

Fama, E. F., \& K. R. French (2008). Dissecting Anomalies. Journal of Finance 63, 2971-2995.

Fisher, G., Shah, R. \& S. Titman (2016). Combining Value and Momentum. Journal of Investment Management 14, 33-48 
Grobys, K. (2016). Another look at momentum crashes: Momentum in the European Monetary Union. Applied Economics 48, 1759-1766.

Grobys, K. (2018). Risk-managed 52-week high industry momentum, momentum crashes and hedging macroeconomic risk. Quantitative Finance 18, 1233-1247.

Lakonishok, J., Shleifer, A. \& R. Vishny (1994). Contrarian Investment, Extrapolation, and Risk. Journal of Finance 49, 1541-1578.

Timo, L. \& P. Eero (2009). Performance of the Value Strategies in the Finnish Stock Markets. Journal of Money, Investment and Banking 8, 5-24.

Timo, L. (2012). Combining value and momentum indicators in varying stock market conditions: The Finnish evidence. Review of Accounting and Finance 11, 400-447

Lee, C.M.C. \& B. Swaminathan (2000). Price Momentum and Trading Volume. Journal of Finance 55, 2017-2069

Moreira, A. and Muir, T. (2017). Volatility managed portfolios. Journal of Finance 72, 16111644.

Newey, W. K., \& West, K. D. (1987). A simple, positive semi-definite, heteroskedasticity and autocorrelation consistent covariance matrix. Econometrica 55, 703-708. 


\section{Figures}

Figure 1. Value, momentum and 50/50 portfolios (top third equal weighted)

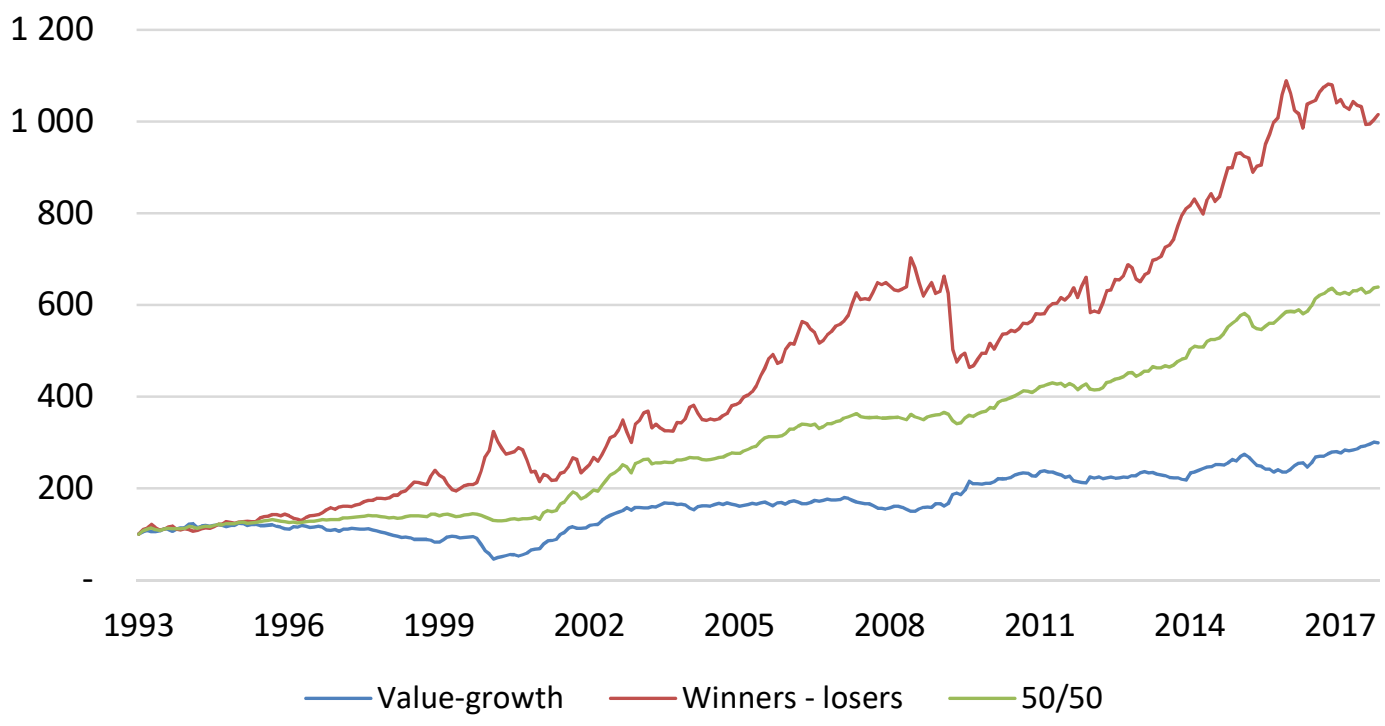

Figure 2. Cumulative returns of combination portfolios and market equal weighted

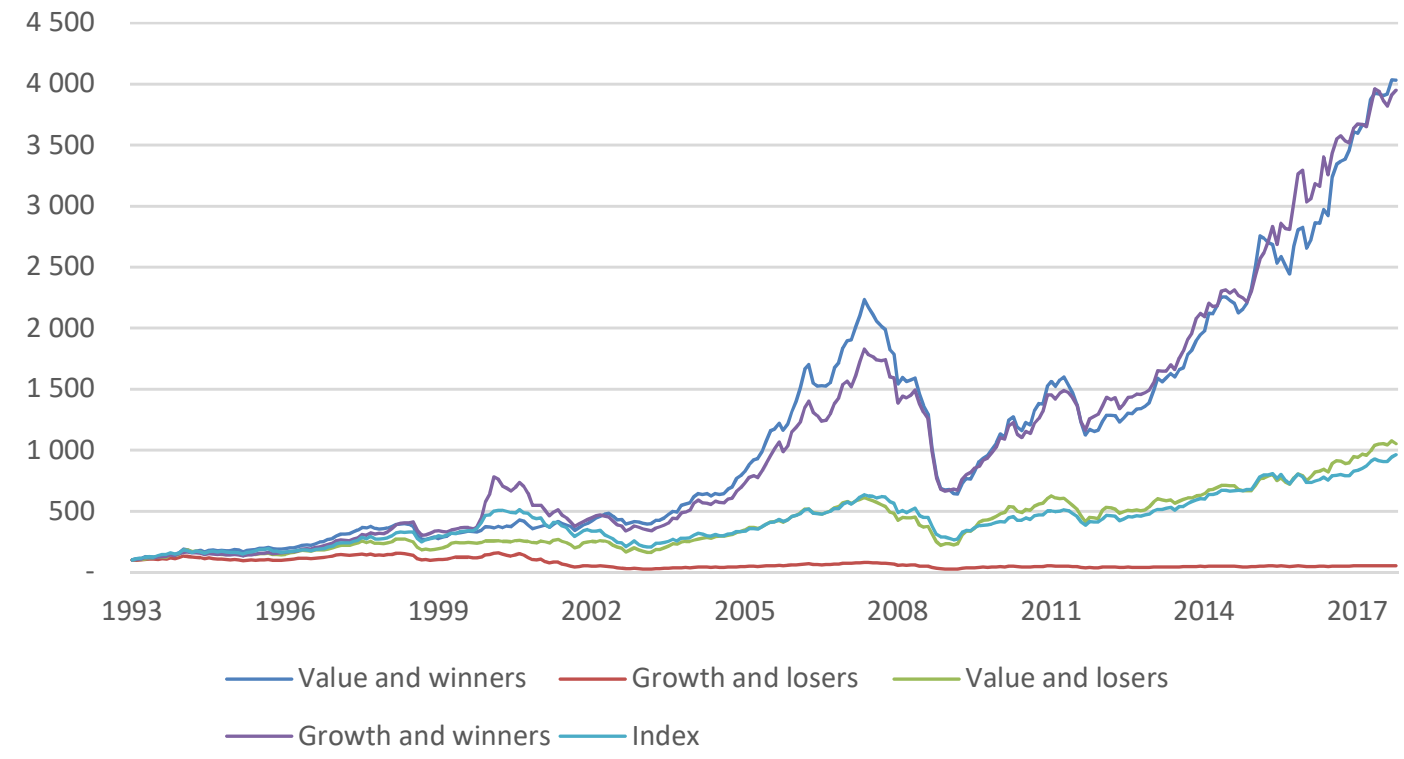




\section{Tables}

\section{Table 1. Average payoffs of the momentum strategy}

\begin{tabular}{|c|c|c|c|}
\hline \multicolumn{4}{|c|}{ Panel A. All stocks equally weighted } \\
\hline & Winners & Losers & Winners minus losers \\
\hline Monthly return & $2.47 * * *(3.56)$ & $0.75(1.54)$ & $1.72 * * *(2.93)$ \\
\hline Monthly alpha & $1.74 * *(2.54)$ & $-0.28(-1.11)$ & $2.01 * * *(2.99)$ \\
\hline STDEV & $38.5 \%$ & $21.7 \%$ & $37.5 \%$ \\
\hline Sharpe ratio & 0.77 & 0.27 & 0.61 \\
\hline Sortino ratio & 12.42 & 1.67 & 8.89 \\
\hline Portfolio beta & 0.63 & 0.88 & -0.25 \\
\hline \multicolumn{4}{|c|}{ Panel B. Top third equally weighted } \\
\hline & Winners & Losers & Winners minus losers \\
\hline Monthly return & $1.95^{* * *}(4.61)$ & $1.10 * * *(2.61)$ & $0.86^{* * *}(3.57)$ \\
\hline Monthly alpha & $0.92 * * *(4.46)$ & $-0.01(-0.06)$ & $0.93 * * *(4.21)$ \\
\hline STDEV & $19.0 \%$ & $20.2 \%$ & $13.3 \%$ \\
\hline Sharpe ratio & 1.16 & 0.51 & 0.81 \\
\hline Sortino ratio & 7.34 & 3.02 & 4.72 \\
\hline Portfolio beta & 0.89 & 0.95 & -0.06 \\
\hline
\end{tabular}

*** Statistically significant on a 1\% level.

** Statistically significant on a 5\% level. 
Table 2. Average payoffs of the value strategy

Panel A. All stocks equally weighted

$\begin{array}{llll} & \text { Value } & \text { Growth } & \text { Value minus growth } \\ \text { Monthly return } & 2.05^{* * *(4.30)} & 0.80^{*}(1.71) & 1.25^{* * *(4.12)} \\ \text { Monthly alpha } & 1.16^{* * *(4.02)} & -0.23(-0.99) & 1.39 * * *(4.95) \\ \text { STDEV } & 20.9 \% & 19.5 \% & 14.5 \% \\ \text { Sharpe ratio } & 1.12 & 0.33 & 1.11 \\ \text { Sortino ratio } & 9.17 & 1.85 & 9.87 \\ \text { Portfolio beta } & 0.76 & 0.88 & -0.12\end{array}$

Panel B. Top third equally weighted

\begin{tabular}{llll} 
& Value & Growth & Value minus growth \\
Monthly return & $1.50^{* * *(3.69)}$ & $1.06^{* *}(2.28)$ & $0.44(1.50)$ \\
Monthly alpha & $0.49 * *(2.05)$ & $-0.08(-0.41)$ & $0.58^{* *}(2.08)$ \\
STDEV & $18.5 \%$ & $20.3 \%$ & $12.2 \%$ \\
Sharpe ratio & 0.85 & 0.48 & 0.44 \\
Sortino ratio & 5.11 & 2.70 & 2.49 \\
Portfolio beta & 0.86 & 0.98 & -0.12 \\
\hline
\end{tabular}

*** Statistically significant on a 1\% level.

** Statistically significant on a 5\% level.

* Statistically significant on a $10 \%$ level. 
Table 3. Comparison of the average payoffs

\begin{tabular}{|c|c|c|c|}
\hline \multicolumn{4}{|c|}{ Panel A. All stocks equally weighted } \\
\hline & Value minus growth & Winners minus losers & $50 / 50$ \\
\hline Monthly return & $1.25 * * *(4.12)$ & $1.72 * * *(2.93)$ & $1.48 * * *(4.79)$ \\
\hline Monthly alpha & $1.39 * * *(4.95)$ & $2.01 * * *(2.99)$ & $1.70 * * *(4.73)$ \\
\hline STDEV & $14.5 \%$ & $37.5 \%$ & $19.3 \%$ \\
\hline Sharpe ratio & 1.11 & 0.61 & 1.00 \\
\hline Sortino ratio & 9.87 & 8.89 & 23.82 \\
\hline Portfolio beta & -0.12 & -0.25 & -0.18 \\
\hline \multicolumn{4}{|c|}{ Panel B. Top third equally weighted } \\
\hline & Value minus growth & Winners minus losers & $50 / 50$ \\
\hline Monthly return & $0.44 * * *(1.50)$ & $0.86 * * *(3.57)$ & $0.65 * * *(4.94)$ \\
\hline Monthly alpha & $0.58 * * *(2.08)$ & $0.93 * * *(4.21)$ & $0.75 * * *(4.78)$ \\
\hline STDEV & $12.2 \%$ & $13.3 \%$ & $6.8 \%$ \\
\hline Sharpe ratio & 0.44 & 0.81 & 1.18 \\
\hline Sortino ratio & 2.49 & 4.72 & 9.35 \\
\hline Portfolio beta & -0.12 & -0.06 & -0.09 \\
\hline
\end{tabular}

*** Statistically significant on a $1 \%$ level.

** Statistically significant on a 5\% level.

* Statistically significant on a 10\% level. 
Table 4. Average payoffs of the long-only combination portfolios using $50 \%$ limits

\begin{tabular}{lllll}
\hline \multicolumn{5}{c}{ Top third equal weighted } \\
\hline & Value and winners & Value and losers & Growth and winners & Growth and losers \\
\hline Monthly return & $1.66^{* * *}(3.95)$ & $1.22^{* * *}(2.97)$ & $1.68^{* * *}(3.69)$ & $0.25(0.56)$ \\
Monthly alpha & $0.72 * *(2.56)$ & $0.18(0.89)$ & $0.61^{* * *}(2.98)$ & $-0.88^{* * *}(-4.18)$ \\
STDEV & $18.2 \%$ & $19.2 \%$ & $19.7 \%$ & $20.6 \%$ \\
Sharpe ratio & 0.99 & 0.62 & 0.92 & -0.01 \\
Sortino ratio & 5.80 & 3.79 & 5.74 & -0.07 \\
Portfolio beta & 0.81 & 0.89 & 0.92 & 0.97 \\
\hline
\end{tabular}

*** Statistically significant on a $1 \%$ level.

Table 5. Average payoffs of long-short combination portfolios using 50\% limits

\begin{tabular}{llll}
\hline \multicolumn{3}{c}{ Top third equally weighted } \\
\hline High rank & Low rank & High - low \\
Monthly return & $1.85^{* * *}(4.84)$ & $0.25(0.56)$ & $1.60^{* * *}(7.01)$ \\
Monthly alpha & $0.90^{* * *}(4.12)$ & $-0.88^{* * *}(-4.18)$ & $1.79^{* * *}(6.87)$ \\
STDEV & $17.4 \%$ & $20.6 \%$ & $11.6 \%$ \\
Sharpe ratio & 1.18 & -0.02 & 1.81 \\
Sortino ratio & 7.35 & -0.08 & 16.44 \\
Portfolio beta & 0.81 & 0.97 & -0.17 \\
\hline
\end{tabular}

*** Statistically significant on a 1\% level. 
Table 6. Average portfolio payoffs during the Global financial crisis period from January 2008-December 2010

\begin{tabular}{lcc}
\hline Portfolio & Payoff & $\begin{array}{c}\text { Portfolio payoff }-\mathbf{5 0 / 5 0} \\
\text { combination portfolio }\end{array}$ \\
\hline 50/50 Combination & $0.51^{* *}$ & - \\
Portfolio & $(2.00)$ & $0.71 * *$ \\
& $1.22 * * *$ & $(2.06)$ \\
High Rank -Low Rank & $(2.80)$ & -0.17 \\
& 0.34 & $(-0.44)$ \\
Value and winners - growth & $(0.67)$ & \\
and losers & & \\
*** Statistically significant on a 1\% level. & & \\
$* *$ Statistically significant on a 5\% level. & &
\end{tabular}




\section{Appendix}

\section{Figure A.1. Time series evolutions of foreign exchange rates}

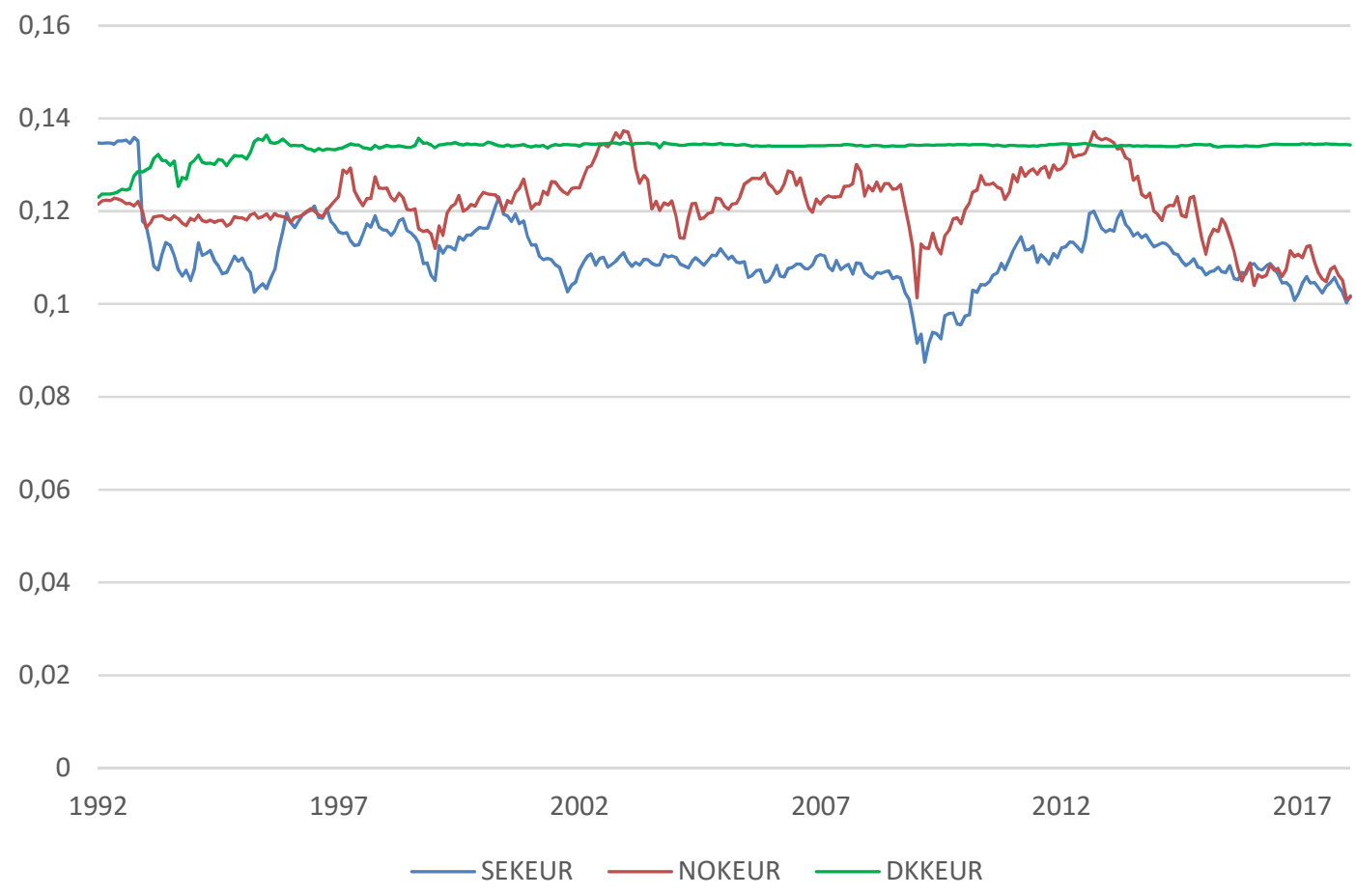


Figure A.2. Nordic IBOR-rate and U.S. T-Bills development

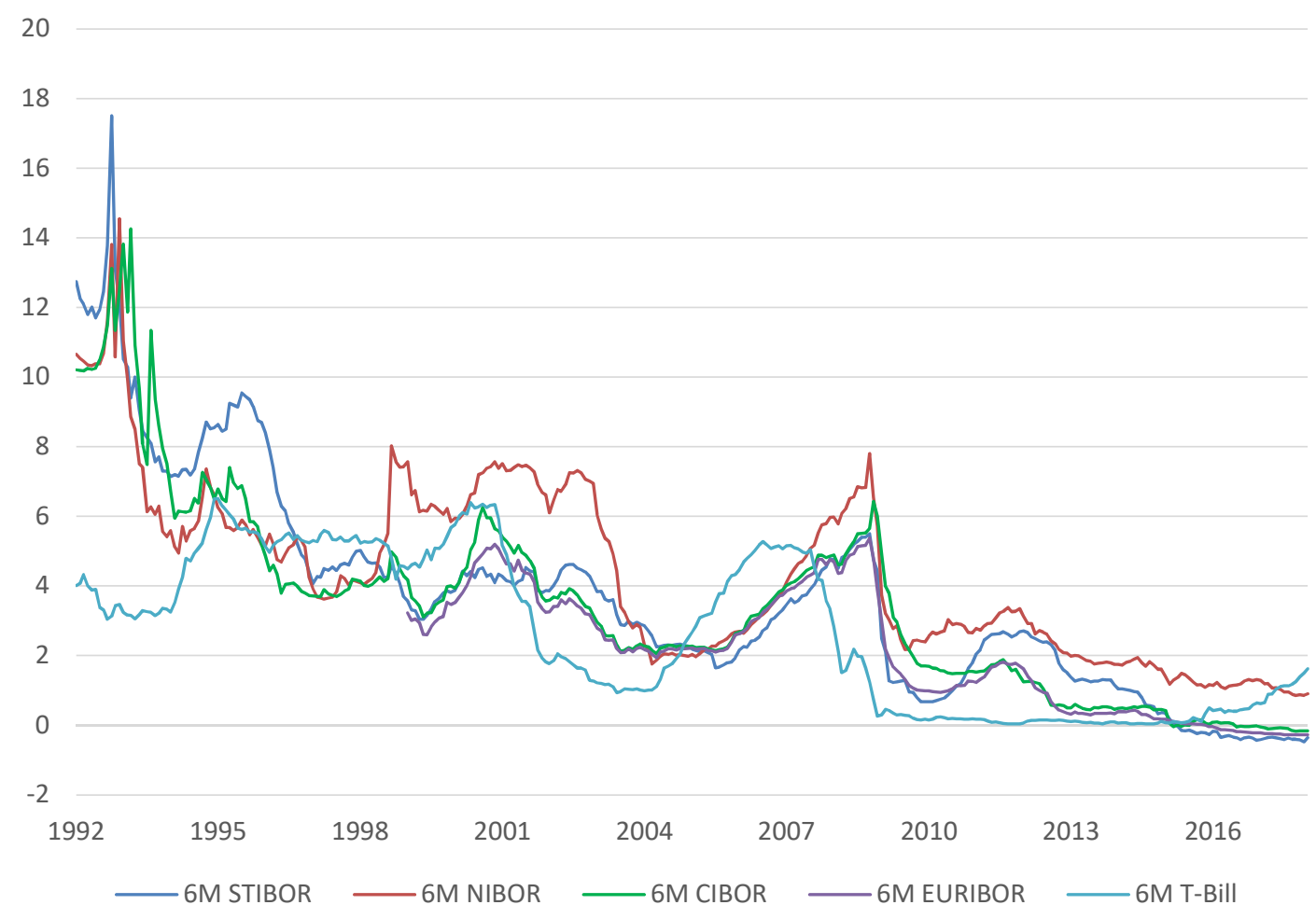


Figure A.3. Cumulative returns of ranking scheme portfolios

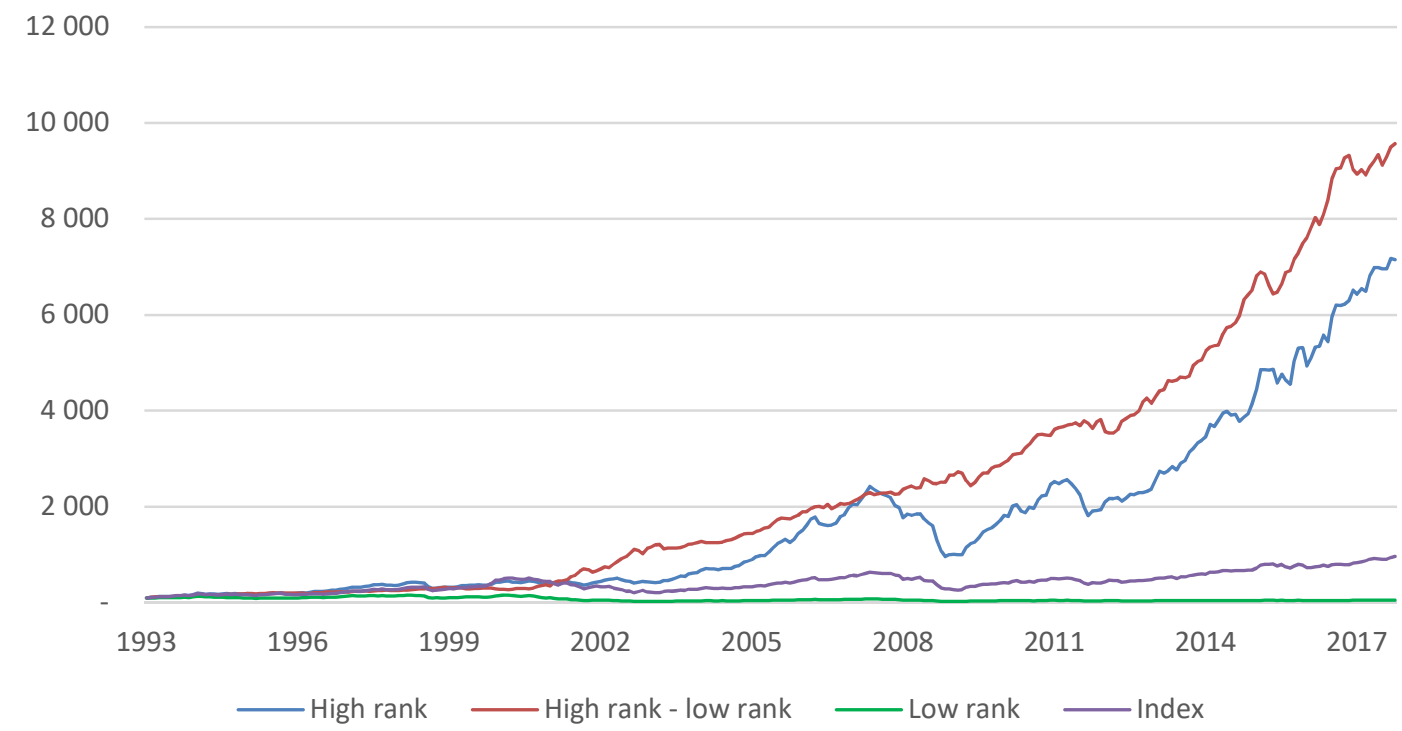

Table A.1. Number of companies in the sample

\begin{tabular}{llllll}
\hline & Denmark & Finland & Norway & Sweden & Total \\
\hline $\begin{array}{l}\text { Max number of } \\
\text { stocks }\end{array}$ & 214 & 150 & 236 & 493 & 1052 \\
$\begin{array}{l}\text { Min number of } \\
\text { stocks }\end{array}$ & 133 & 100 & 95 & 164 & 543 \\
$\begin{array}{l}\text { Number of stocks of } \\
\text { average }\end{array}$ & 178 & 126 & 181 & 359 & 844 \\
$\begin{array}{l}\text { Average market } \\
\text { value in total M€ }\end{array}$ & 140000 & 137000 & 116000 & 307000 & 700000 \\
\hline
\end{tabular}


Table A.2. Correlation matrix of value and momentum

\begin{tabular}{lrrrrrr}
\hline & Value & Growth & Winners & Losers & $\begin{array}{r}\text { Value }- \text { Winners - } \\
\text { growth }\end{array}$ & $\begin{array}{r}\text { losers } \\
\text { Value }\end{array}$ \\
Growth & 1.000 & & & & & \\
Winners & 0.807 & 1.000 & & & & \\
Losers & 0.829 & 0.938 & 1.000 & & & \\
Value-growth & 0.927 & 0.846 & 0.771 & 1.000 & & \\
Winners - losers & 0.175 & -0.441 & -0.303 & -0.002 & 1.000 & \\
\hline
\end{tabular}

Table A.3. Number of stocks in portfolios

\begin{tabular}{lcccc}
\hline & Value and winners & Value and losers & Growth and winners & Growth and losers \\
\hline Average & 47 & 65 & 64 & 48 \\
Max & 74 & 102 & 106 & 78 \\
Min & 13 & 20 & 20 & 14 \\
\hline
\end{tabular}

Table A.4. Correlation matrix of different combination strategies

\begin{tabular}{lrrrr}
\hline & $\begin{array}{r}\text { High rank - low } \\
\text { rank }\end{array}$ & $50 / 50$ & $\begin{array}{c}\text { Value and winners - } \\
\text { growth and losers }\end{array}$ & Index \\
\hline High rank - low rank & 1.00 & & & \\
$50 / 50$ & 0.90 & 1.00 & & \\
Value and winners - growth and & & & & \\
losers & 0.94 & 0.89 & -0.24 & 1.00 \\
Index & -0.26 & -0.24 & \\
\hline
\end{tabular}

